\title{
La religión en la historia
}

Alfred North Whitehead

King's Chapel, febrero de 1926

\section{Definición de religión}

En las siguientes conferencias me propongo considerar las diversas justificaciones posibles para la creencia religiosa. Toda generación debe afrontar esta inquietud de una forma $u$ otra. Es propio de la religión que la humanidad modifique constantemente su actitud ante ella.

El contraste entre la religión y las verdades elementales de la aritmética ilustra lo que intento decir. Hace innumerables eras, las doctrinas básicas de la aritmética brotaron de la mente humana; y desde entonces, el dogma de que tres y dos son cinco ha ejercido ilimitado dominio. Todos compartimos la misma doctrina; y no es necesario estudiar su evolución histórica para comprenderla.

Ahora bien: no tenemos ni idea de lo que, en el ámbito de la doctrina, implica la religión. No hay una definición general de religión en la que podamos estar de acuerdo, ni una forma de distinguir la religión "buena" de la "mala"; no hay consenso en cuanto a qué puede ser una creencia religiosa válida; ni siquiera en lo que queremos decir al hablar de verdad religiosa. Por todo esto, necesitamos demostrar si discutir sus principios generales es de valor, dado que la religión ha sido un factor incuestionable de la historia humana.

Hay todavía otra diferencia. En lo que toca a las verdades generales, lo que suele estar en disputa es dudoso; y, en igualdad de condiciones, lo dudoso es relativamente intrascendente. Nos guardamos de orientar nuestras acciones bajo principios inciertos. Si no sabemos cuánto es 69 por 67, aplazamos cualquier acción hasta haberlo averiguado. Podemos dejar de lado este pequeño enigma aritmético hasta darle respuesta; y podemos responderlo sin mayor dificultad más allá de toda duda.

Pero no hay igualdad de condiciones entre religión y aritmética. Se usa la aritmética mientras que se es religioso. En la medida en que la naturaleza de uno incluye una multitud de elementos, incluye también la aritmética; pero como condición necesaria, no como agencia transformadora. Nadie puede "justificar" sus creencias en la tabla de multiplicar; mas de un modo u otro, la justificación es la base de toda religión. El carácter crece de acuerdo con la fe. Esta es la verdad religiosa fundamental de la que nadie puede escapar. La religión es la fuerza de la creencia que purifica interiormente al creyente. $\mathrm{Y}$, por consiguiente, la virtud religiosa fundamental es la sinceridad, la más penetrante sinceridad.

Así pues, podemos definir la religión, en su aspecto doctrinario, como un sistema de verdades generales que, si se abrigan sinceramente y se aferran con valor, transforman profundamente el carácter. 
A la larga, el carácter y la conducta dependen de las convicciones más íntimas. La vida es, en sí misma, un hecho interno, antes de externalizarse y relacionarse con los otros. La conducta externa de la vida está condicionada por el ambiente; mas su colofón, del que depende su valor, proviene de la vida interior, de la auto-realización de lo existente. La religión es el arte y la teoría de la vida interior del ser humano, en tanto depende del ser humano mismo y de lo que hay de permanente en la naturaleza de las cosas.

Esta teoría se opone a la noción de que la religión es ante todo un hecho social. No hay tal cosa como la existencia aislada e independiente; por ende, los hechos sociales son de gran importancia para la religión. No se puede abstraer a la sociedad del ser humano, y si bien gran parte de la psicología es comportamiento de masas, de rebaño, la emoción colectiva deja intacto el tremendo y postrer hecho del ser humano consciente de sí, solo consigo mismo, con su propia naturaleza.

La religión es lo que el ser humano hace con su soledad. Si evoluciona satisfactoriamente, atraviesa tres etapas: de Dios, el vacío, a Dios, el Enemigo; de Dios, el Enemigo a Dios, el Compañero.

Por tanto, religión es soledad; y si nunca se está solo, nunca se es religioso. El entusiasmo colectivo, los festivales, las instituciones, las iglesias, las Biblias, los códigos morales, son las trampas de la religión, sus encarnaciones pasajeras. Pueden ser útiles, y también perjudiciales; pueden ser decretos autorizados o momentáneos expedientes. La finalidad de toda religión se encuentra mucho más allá.

Por consiguiente, lo que la religión debe engendrar es el valor del carácter individual. Pero este valor puede ser positivo o negativo, bueno o malo. La religión no tiene por qué ser necesariamente buena y puede ser, de hecho, terriblemente mala. El mal que se entreteje con el tapiz del mundo demuestra que en la naturaleza de las cosas existe también un potencial para la degradación. Uno puede tener experiencias religiosas con el Dios de la Destrucción, el Dios que aplasta con su estela cualquier trascendencia.

No debe cegarnos la idea de que la religión tiene que ser buena, una peligrosa ilusión. Lo que debemos tener presente es su gran importancia, que se evidencia en la historia humana.

\section{El surgimiento de la religión}

Cuando la religión recibe una expresión en la historia humana se muestra en cuatro facetas: el ritual, las emociones, la creencia, la racionalización. Hay un procedimiento organizado y definido, el ritual; hay tipos definidos de expresión emocional; hay una serie determinada de creencias; y hay el ajuste de estas creencias dentro de un sistema, coherente consigo mismo y con el resto de ideas.

La influencia de cada factor a lo largo de las eras ha sido desigual. La idea religiosa emergió gradualmente, al principio casi indistinguible del resto de intereses humanos. Los factores aparecieron en sentido contrario a su importancia: primero el ritual, luego la emoción, luego la creencia y por último la racionalización.

El surgimiento de cada etapa fue gradual; consistió en un aumento del énfasis. Quizá sea erróneo sostener que los últimos dos factores estuvieron alguna vez ausentes; mas, si retrocedemos lo suficiente, descubrimos que son intrascendentes, y que la emoción es tan sólo un efecto secundario del ritual. Más tarde, la emoción toma la posta; y el ritual se usa para generarla. Entonces aparece la 
creencia, en un intento de explicar el conjunto ritual-emoción; y en ella podemos entrever la semilla de la racionalización.

Sólo cuando creencia y racionalización se han establecido, puede descubrirse el valor de la soledad en el corazón mismo de la religión. Las grandes concepciones religiosas que obsesionan a la humanidad son escenas solitarias: Prometeo encadenado a las rocas, la preparación de Mahoma en el desierto, las meditaciones del Buda, el apartado Hombre en la Cruz. En lo más profundo del espíritu religioso está el sentimiento de desamparo, de haber sido abandonado por el propio Dios.

\section{Ritual y emoción}

El ritual antecede a la humanidad. Lo encontramos en los animales, en sus hábitos individuales y sus evoluciones colectivas. Puede definirse como la ejecución habitual de acciones definidas que carecen de relación directa con la preservación orgánica de su actor.

Las bandadas de aves ejecutan sus evoluciones rituales en los cielos; así lo hacen, en Europa, los grajos y los estorninos. El ritual es el resultado más primitivo del exceso de energía y del ocio. Ejemplifica la tendencia de los seres vivos a repetir sus propios actos. Así, las acciones necesarias para la caza de alimento, u otros propósitos provechosos, se repiten sin mayores justificaciones, y con ellas se repite también el placer del ejercicio y la emoción del éxito.

De esta manera, la emoción depende del ritual; y el ritual se repite y perfecciona en pos de la emoción que lo acompaña. Los seres humanos se volvieron artistas del ritual. Fue un descubrimiento tremendo: aprendieron a excitar las emociones, no debido a la imperiosa necesidad biológica, sino por el mero hecho de sentirlas. Mas la emoción sensibiliza al organismo; en consecuencia, involuntariamente, el organismo humano se sensibilizó a armonías que las meras actividades de supervivencia jamás habrían acentuado.

Allí comenzó la humanidad su aventura de curiosidad y sentimiento.

Según esta hipótesis, tanto la religión como el juego y el teatro nacieron del ritual; pues el ritual es el estímulo de la emoción, y un ritual reiterado puede convertirse en religión o en juego dependiendo de la emoción que desencadene. Hasta épocas comparativamente modernas (s. $\mathrm{V}$ aC), los Juegos Olímpicos griegos estaban teñidos de religiosidad; y el festival dionisíaco del Ática concluía con una comedia. Todavía, en el mundo moderno, el domingo es "el día del Señor" (dominus) ${ }^{1}$.

Hay otras formas, aparte del ritual, de estimular artificialmente la emoción; las drogas, por ejemplo. Felizmente, las razas primitivas no podían elegir entre muchas clases de droga. Hay, sin embargo, amplia evidencia del uso religioso de las drogas, en conjunción con el uso religioso del ritual. Según Ateneo de Naucratis, era un deber sagrado del rey persa, en el festival anual del dios Mithra, hacer acto de presencia en el templo en estado de intoxicación. Un resto del sentimiento religioso ante la intoxicación es el uso del vino en la misa, testimonio de la tendencia del ritual de convertir una tosca y primitiva asociación de ideas en un simbolismo sublime.

\footnotetext{
${ }^{1}$ En el original inglés se establece la asociación entre holiday (“día de fiesta”) y holy day (“día sagrado”) (N. del T).
} 
En esta fase primitiva de la religión, dominada por el ritual y la emoción, topamos con fenómenos esencialmente sociales. El ritual es más impactante, y la emoción más intensa, cuando lo practica la sociedad entera. Concomitantemente, los rituales y las emociones colectivas son las fuerzas que unen a las tribus salvajes. Son los primeros atisbos de la vida espiritual que se eleva sobre las tareas animales de supervivencia. De manera recíproca, cuando la religión se deteriora vuelve a hundirse en la sociabilidad.

\section{Creencia}

El ritual y la emoción no pueden mantenerse apartados del intelecto. Puede que la idea de repetir el ritual en pos de la emoción explique la psicología inconsciente de las tribus primitivas; pero es demasiado abstracta para que se percaten de ella. El mito satisface la incipiente necesidad de racionalidad. Los seres humanos descubrieron que practicaban rituales, y que éstos generaban emociones; el mito explica el propósito de ambas. Nace de la vívida fantasía del primitivo en un mundo incomprensible.

Para el primitivo (como lo primitivo que hay en nosotros), el universo no es tanto incomprensible como incomprendido; es decir, indiscriminado, no sometido a análisis. No es un conjunto de sucesos definidos y faltos de explicación, sino un vago trasfondo salpicado de objetos y emociones. Las mínimas condiciones de racionalidad, las interrelaciones que la sustentan, están ausentes. Pero el estadio inicial consiste en un trasfondo indefinido moteado de vívidos actos, discretos pero aislados entre sí. Las rutinas de satisfacción de las necesidades tribales son la excepción a esta regla. Pero lo que yace más allá de estas rutinas es indeterminado e incierto; y cuando es vívido, es también aislado.

El mito que complementa al ritual es una fantasía especialmente vívida, o el recuerdo distorsionado de tal fantasía, que no solamente explica tanto el ritual como la emoción sino que genera la emoción cuando se asocia con el ritual. Así, el mito no solamente permite entender el ritual: además, refuerza su propósito oculto, la obtención de la emoción.

De este modo, ritual, emoción y mito actúan recíprocamente; y los mitos tienen diversos grados de paralelismo con los hechos reales y con las verdades simbólicas, verdades de tal magnitud que únicamente pueden aprehenderse a través de las parábolas. En ocasiones, el mito precede al ritual; mas, en términos generales, la ritualización antecede a la mitología, ya que incluso los animales evidencian ritualizaciones carentes de mitos.

Los mitos subrayan la importancia de una persona o cosa particulares, reales 0 imaginarias. Por consiguiente, en cierto modo, el ritual, sumado a la explicación mitológica, es la adoración primitiva de la cosa o la persona heroicas. Sin embargo, la adoración entre los primitivos casi nunca es desinteresada; conque de la creencia en el mito se sigue la creencia de que algo debe, o bien conseguirse con él, o bien evitarse de él. Así emergen los conjuros, la oración, la alabanza y la absorción ritual del héroe.

Cuando el héroe es una persona, llamamos religión al mito y a su concomitante ritual; cuando es una cosa, los llamamos magia. En la religión se ruega, en la magia se manda. Una importante diferencia es que la religión es progresiva y la magia no (salvo en tanto que la ciencia se deriva de ella). 
Cuando la creencia alcanza este nivel, la religión se convierte en un nuevo agente formativo de la evolución humana. Pues así como el ritual impulsó a la emoción más allá de la respuesta a las necesidades básicas, la religión da lugar a ideas independientes de la presión de las circunstancias. Aquí se apuntaló la imaginación en su camino ascendente; así se separó el pensamiento de los objetos presentes. Sus concepciones, aunque horrendas y toscas, ya no estaban sujetas a la percepción sensible de la inmediatez.

Este es el estadio de las creencias desorganizadas. Posee una peculiar tolerancia: las creencias más disímiles conviven sin dificultad. Hay tan poca coordinación que todas tienen un sitio. Empero, la religión es todavía un fenómeno enteramente social. El culto se extiende a la tribu, o al menos a un grupo social bien definido. Uno no puede renunciar a su secta; mas las sectas no discuten entre sí. Una tribu en la etapa más alta de este estadio posee varios dioses y una caótica plétora de mitos y rituales.

La religión puede ser fuente de progreso, mas no necesariamente, sobre todo si es de esta clase y consiste en un collage de creencias sin examinar. No es difícil que una tribu se estanque con su colección de mitos; puede no haber ningún factor externo que estimule la evolución. De hecho, es aquí donde se encuentra la masa de la humanidad semi-civilizada: en el ritual que satisface, en la creencia satisfecha, sin ningún deseo de trascendencia. Esta religión pasa la prueba pragmática: funciona, y puede, por tanto, pretender el estatuto de verdad.

\section{Racionalismo}

Con el surgimiento del racionalismo entran en escena los mártires. Las fases anteriores han sido esencialmente sociales: muchos eran los llamados, y todos los elegidos. Esta fase final introduce la soledad: $Y$ es estrecha la puerta y angosto el camino que lleva a la vida, y son pocos los que lo encuentran (Mt 7, 14). La religión que olvida este hecho involuciona hacia un barbarismo atávico: apela a la psicología del rebaño y no a las intuiciones de unos pocos.

Ésta es una fase muy moderna de la religión: más o menos los últimos seis mil años. Evidentemente, no tiene sentido fijar una duración exacta: podemos ampliarla para incluir algún movimiento precoz o reducirla para excluir los restos de las fases previas. Este movimiento se ha extendido a todas las razas civilizadas de Europa y Asia. Al principio, Asia fue un terreno prolífico; pero, en los últimos dos mil años, Europa ha marcado el paso. Cabe señalar que los dos mejores ejemplos de religión racionalista han florecido sobre todo fuera de sus países originarios.

La Biblia es sin duda el documento más completo de la racionalización de la religión; aunque sólo es relevante como tal para la región comprendida entre el Tigris y el Nilo. Despliega la progresiva soledad de la religión: al principio, formas de pensar predominantes; luego, la protesta de los profetas, figuras aisladas que denuncian y agitan la nación hebrea; luego, la aparición de un hombre, con doce discípulos, que sufrió el rechazo casi total de su sociedad; por último, otro hombre que adaptó su doctrina para el público común, un hombre que (y esto es de gran importancia) no accedió a ella de primera mano. En sus manos, la doctrina ganó algunas cosas y perdió otras; afortunadamente también conservamos los Evangelios.

Salta a la vista que el período de seis mil años que he adelantado, aparte de concordar con la evidencia disponible, corresponde a la cronología bíblica. Nosotros, los europeos y los americanos, 
somos herederos de los movimientos religiosos allí condensados. Para ser relevante, la discusión de los métodos religiosos y sus justificaciones debe tomar la Biblia como ejemplo. Empero, las afirmaciones generales también deben contrastarse con el budismo y el islamismo, aunque no sean analizados explícitamente.

En la religión racional, creencias y rituales se han reorganizado para convertirlas en el centro de una forma de vida coherente y ordenada. Esta coherencia se aplica tanto a la elucidación del pensamiento cuanto a la necesidad de que la acción se dirija hacia un propósito común que la ética haya aprobado.

La religión ocupa una posición peculiar entre la metafísica más abstracta y los principios particulares que rigen los ámbitos más concretos de la experiencia. La relevancia de sus conceptos sólo puede discernirse en escasos momentos de lucidez; y, al menos para la mayoría de nosotros, sólo a instancias de un señalamiento externo. Así pues, la religión se funda en una estrecha gama de la totalidad de experiencias de un pueblo. Por una parte, la religión es uno más de los intereses específicos de la humanidad cuyas verdades son de validez limitada. Por otra, la religión afirma que sus conceptos, aunque derivados de experiencias particulares, tienen validez universal, debiendo utilizarse para el ordenamiento de la totalidad de la experiencia en virtud de la fe.

La religión racional apela a la intuición directa de las ocasiones excepcionales y al poder aclarador de sus conceptos para el resto de ocasiones. Nace de lo que es excepcional, pero se extiende a lo general. La doctrina de la religión racional pretende ser una metafísica derivada de la experiencia fuera de lo corriente del espíritu humano en sus momentos más penetrantes. En teoría, la religión racional hubiera podido surgir sin necesidad de las religiones sociales del ritual y la creencia mítica. Era así como los teólogos hacían apología de sus religiones antes de la aparición del sentido histórico. Empero, la historia de la religión en general, y la de la Biblia en particular, desmiente esa suposición. La religión racional brotó de las transformaciones de las formas religiosas previas. Llegó un momento en el que las viejas formas no podían abarcar las ideas nuevas; las religiones modernas provienen de tales crisis de desarrollo. $\mathrm{Y}$ el desarrollo no se detuvo: únicamente adquirió formas mejores de expresión.

La aparición de la religión racional estuvo determinada por el progreso general de las azas que la dieron a luz. Hacían falta, para ello, intuiciones éticas e ideas generales; ideas que, salidas de las brillantes mentes individuales, se plasmaron en formas estables de expresión que hicieron posible recordarlas y comunicarlas. Uno sólo puede hablar de "misericordia" con gente que ya es misericordiosa en algún ámbito de su vida.

Un lenguaje no permite la expresión de todas las ideas posibles. Es un medio limitado que expresa las ideas más corrientes y necesarias del grupo que lo desarrolló. Hace muy poco tiempo, comparativamente hablando, que el lenguaje dispone de términos generales. $Y$ estos términos necesitan de una literatura que, manteniéndolos en circulación, los defina permanentemente por medio del uso.

Por tanto, la manipulación de ideas generales es una adquisición reciente. No quiero decir que los cerebros de los seres humanos no fueran capaces de concebirlas; sino que fueron necesarias varias eras para que desarrollaran, primero, los utensilios, y segundo, los hábitos, que han hecho posible y común el pensamiento generalizador. Este proceso hubiera podido acortarse si los seres humanos hubieran tenido contacto con una raza superior, directamente o por vía de su literatura. De hecho, es así como se han venido desarrollando las razas del norte de Europa. Igualmente (y como ha ocurrido 
en la realidad) un sistema social que promueve el desarrollo del pensamiento puede acelerar este proceso. El lenguaje y la sociedad han crecido al unísono.

Grande ha sido la influencia de las formas religiosas anteriores basadas en el ceremonial, el mito y la socialidad; y desigual el valor que se les ha atribuido. El racionalismo luchó por transformar los modos más primitivos durante los mil años anteriores a la era cristiana. El resultado fue la síntesis que hemos heredado en la forma de las grandes religiones contemporáneas. Las ideas religiosas devinieron más racionales y generales; y los mitos se convirtieron en descripciones de eventos históricos que ejemplificaban las ideas generales a la perfección.

Así se acogió la crítica racional; se pasó de la costumbre tribal a la intuición individual directa, fuese ética, metafísica o lógica: Porque yo quiero amor, no sacrificios; conocimiento de Dios, que no holocaustos, exclama, por boca de Oseas $(6,6)$, Jehová, cuando apela a la crítica individual (fundada en la intuición ética directa) de la costumbre tribal.

De este modo, la religión abdicó de sus aspectos comunales para aproximarse a formas individualistas. La unidad religiosa era el individuo, no la comunidad; la danza tribal se volvió menos importante que la oración en privado; y ésta se convirtió (al menos, para una minoría) en el intento de justificarse por vía del auto-descubrimiento.

Es así que, hoy por hoy, son los franceses quienes van al cielo, y no Francia; los chinos quienes logran el nirvana, y no la China.

En este período de lucha, los innovadores juzgaron a las religiones tradicionales con suma severidad. La Biblia está llena de condenas a la idolatría; y contiene indicios de un rechazo aún mayor: Odio, aborrezco vuestras fiestas, y no me complazco en vuestras solemnidades, dice Jehová por medio de Amós $(5,21)$.

Hoy nos hace falta este espíritu crítico. La historia es un registro de horrores cometidos en nombre de la religión. Sacrificios humanos (sobre todo de niños), canibalismo, orgías, supersticiones, odio a las demás razas, hábitos degradantes, histeria, fanatismo: todo esto y más se le puede achacar. La religión es el último refugio de la barbarie. Los hechos desmienten la asociación entre religión y bondad. La religión puede ser (y ha sido) el principal instrumento del progreso. Pero ésta ha sido la excepción más que la regla: Porque muchos son los llamados, pero pocos los elegidos. (Mt 22, 14).

\section{El ascenso del ser humano}

En cada época emergen factores nuevos que influirán en el ascenso (o descenso) de la humanidad. Durante el milenio anterior al nacimiento de Cristo las religiones comunales dejaron de ser motores del progreso. Tuvieron, en general, un benéfico efecto: vivificar los sentimientos de unidad y responsabilidad social. La emoción de estar íntegramente entregado a la tribu se expresó en los cultos comunitarios, que fomentaron, a su vez, la aparición de intereses distintos de la mera supervivencia. $Y$ surgieron creencias concretas que justificaban estas emociones.

Mas hubo un momento en que detuvieron su avance, aunque seguían siendo necesarias para preservar la estructura social. Habían cumplido su tarea. Protegían las virtudes tradicionales que habían llevado su raza a la grandeza; pero se oponían a las novedosas virtudes que intentaban 
convertir el mundo en la Ciudad de Dios. Eran religiones del término medio; y el término medio está reñido con el ideal.

El pensamiento humano había trascendido el horizonte limitado de su propia sociedad: la noción del mundo en su totalidad penetró en la conciencia humana, gracias, en parte, a las facilidades (antes inexistentes) para viajar solo con libertad. La tribu que atraviesa territorios peligrosos puede adquirir nuevas ideas; pero su sentido de unidad tribal se fortalece ante este entorno hostil.

En cambio, el individuo que viaja entabla relaciones con los extraños en términos benignos. Y cuando regresa a casa, su vida y su ejemplo promueven el hábito de pensar desapasionadamente sobre lo que hay más allá de la tribu. Hay en la historia de la religión racional muchos relatos de personas que se desentienden de sus rutinas sociales. En la Biblia, por ejemplo: Abraham anduvo errante, los judíos estuvieron exiliados en Babilonia por dos generaciones, Saulo se convirtió en San Pablo en medio de un viaje y elaboró sus doctrinas a lo largo de muchos otros. El suyo fue el milenio de los viajes: Herodoto, Tucídides, Platón, Jenofonte, Aristóteles, para citar a los griegos. Los imperios y la infraestructura mercantil hicieron de los viajes un hecho corriente: todo el mundo viajaba para ir al encuentro de un nuevo mundo. Había nacido la conciencia global.

India y China la obtuvieron de modos diferentes, aunque en relación con los mismos factores. La separación del individuo de su ambiente social inmediato dio un gran empuje al pensamiento.

Ahora bien: en lo tocante a la religión, la conciencia global y la conciencia social se diferencian en sus respectivas concepciones del bien. La conciencia social se preocupa sólo de los individuos que uno conoce (y estima) personalmente; por ende, el bien va ligado a la supervivencia. La conducta es buena si mueve a las fuerzas superiores a protegernos, y mala si las irrita en contra nuestra. Esta religión es una forma de diplomacia. La conciencia global es desapegada; supone que las cosas poseen una bondad esencial. Los individuos no importan, porque no son conocidos. La idea (un poco profana) de la bondad de Dios desplaza a la de la voluntad divina. En una religión comunal se estudia la voluntad divina con el fin de conseguir su beneplácito; en una religión racionalizada gracias a la concepción global, se estudia Su bondad con el fin de aproximarse a ella. Esto es lo que distingue al enemigo que uno apacigua del compañero que uno imita.

\section{El contraste final}

Vemos, gracias a este resumen histórico, que la religión racional es consecuencia de la conciencia global. La reacción consciente de la naturaleza humana a la organización social domina las últimas fases de la religión comunitaria. Esta reacción es en parte emoción revestida de creencia y rito y, en parte, la justificación racional de la conducta que contribuye al mantenimiento de la sociedad. La religión racional es la reacción consciente y comprehensiva de los seres humanos ante el universo del que forman parte.

La religión comunitaria llegó casi hasta lo racional. Su última fase en occidente fue la religión del imperio romano, que adoptaba una visión extremadamente amplia de la estructura social. El culto del Imperio era más o menos la religión que podría inventar hoy una facultad universitaria de derecho, consciente de que la mera represión penal no impide el azote del crimen. De hecho, basta con estudiar la mentalidad del emperador Augusto y sus colaboradores para comprobar que esto no está muy lejos de la verdad. 
Los judíos encontraron otra forma de religión comunal, cuyas ideas hacían depender la naturaleza de las cosas de su importancia para la raza hebrea. Era éste un compromiso eficaz pero inestable: el tipo de religión al que las sociedades tienden a volver en busca de un refugio. Es la religión del estadista, el industrial y el reformista contemporáneos. Entre los judíos dio como resultado el nacimiento del cristianismo y la diáspora a manos del ejército romano; entre nosotros contribuyó al advenimiento de nuestra última Gran Guerra. Conlleva la exageración mórbida de la autoconciencia nacionalista; le falta el ingrediente del reposo. La globalidad es la sal de la religión.

Tras la cristianización del imperio romano el mundo podía escoger entre dos religiones racionales: el budismo y el cristianismo. Por supuesto, ambas tenían multitud de competidores; pero los dejaron atrás en claridad, generalidad, respetabilidad moral, poder de supervivencia y capacidad de expansión. Luego hubieron de afrontar el reto del islamismo. Pero son, aún hoy, las dos religiones verdaderamente "católicas" (esto es, universales); y si comparamos su situación actual con su historia, hemos de concluir que están en decadencia. Han perdido su influencia sobre la humanidad. 